\title{
Proteinuria and serum creatinine after 12 months of treatment for lupus nephritis as predictors of long-term renal outcome: a case-control study
}

Fernanda Nogueira Holanda Ferreira Braga $2^{2^{*}}$, Marta Maria das Chagas Medeiros ${ }^{1}$, Antonio Brazil Viana Junior ${ }^{1}$, Matheus Eugênio de Sousa Lima², Levi Coelho Maia Barros², Marcelo Ximenes Pontes²,

Allysson Wosley de Sousa Lima² and Paula Frassinetti Castelo Branco Camurça Fernandes²

\begin{abstract}
Background: Lupus nephritis (LN) is a major source of morbidity and mortality in patients with systemic lupus erythematosus (SLE), with 10-25\% of patients progressing to end-stage renal disease (ESRD).

Objective: This study aims to elucidate the predictive capabilities of 24-h proteinuria (24PTU) and serum creatinine $(\mathrm{s} C \mathrm{r})$ after 12 months of treatment with respect to long-term renal outcomes in $\mathrm{LN}$ in a single-center cohort of $\mathrm{LN}$ patients.

Methods: A retrospective analysis was performed on 214 patients diagnosed with LN followed in our center. Values of 24PTU and sCr were assessed at baseline and after 3,6 and 12 months, and after 5 years and/or the last evaluation. Chronic kidney disease (CKD) was defined as an estimated glomerular filtration rate (eGFR) $<60 \mathrm{~mL} / \mathrm{min} / 1.73 \mathrm{~m}^{2}$ for 3 months or longer. End-stage renal disease (ESRD) was defined as the need for permanent dialysis. Receiver operating characteristics curves (ROC) were used to test the best cut-off value of $24 \mathrm{PTU}$ and sCr at 12 months who predict bad long-term renal outcomes.
\end{abstract}

Results: The mean follow-up period was $11.2 \pm 7.2$ years. The best cut-off values for $24 \mathrm{PTU}$ and $\mathrm{s} C \mathrm{r}$ as predictor of CKD were, respectively, $0.9 \mathrm{~g} / 24 \mathrm{~h}$ and $0.9 \mathrm{mg} / \mathrm{dL}$. ROC curve for 24PTU had a slightly lower performance than ROC curve for $\mathrm{s} C r$ as predictor for $\mathrm{CKD}$ (PTU AUC $=0.68$; $\mathrm{s} C r \mathrm{AUC}=0.70$ ), but sensitivity and specificity were better for 24PTU (24PTU: sensitivity $=63.5 \%$, specificity $=71.2 \%$; $\mathrm{SCr}$ : sensitivity $=54.8 \%$, specificity $=75.3 \%)$. When the outcome was ESRD the best cut-off points were $0.9 \mathrm{~g} / 24 \mathrm{hs}$ and $1.3 \mathrm{mg} / \mathrm{dL}$ for $24 \mathrm{PTU}$ and $\mathrm{sCr}$, respectively, and the curve performance was better for 24PTU (PTU AUC $=0.72 ; \mathrm{sCr}$ AUC $=0.61$ ).

Conclusions: In this ethnically diverse population with $L N$ followed for a long time (> 10 years), levels of 24PTU $>0.9$ / day at 12 months was a good predictor of bad long-term renal outcome. The serum creatinine $>0.9 \mathrm{mg} / \mathrm{dL}$ and $>1.3 \mathrm{mg} / \mathrm{dL}$ at 12 months were also good predictors of CKD and ESRD, respectively. Patients with $24 \mathrm{PTU}<0.9 \mathrm{~g} /$ day and $\mathrm{s} C \mathrm{r}<1.3 \mathrm{mg} / \mathrm{dL}$ at 12 months are not likely to develop ESRD because of the high negative predictive values

\footnotetext{
*Correspondence: fnhfb@yahoo.com.br

${ }^{2}$ Centro de Ciências da Saúde, Universidade Estadual Do Ceará, Avenida

Dr. Silas Munguba, 1700, Itaperi, Fortaleza, Ceará, Brazil

Full list of author information is available at the end of the article
}

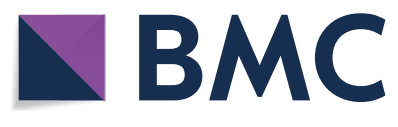

(c) The Author(s) 2021. Open Access This article is licensed under a Creative Commons Attribution 4.0 International License, which permits use, sharing, adaptation, distribution and reproduction in any medium or format, as long as you give appropriate credit to the original author(s) and the source, provide a link to the Creative Commons licence, and indicate if changes were made. The images or other third party material in this article are included in the article's Creative Commons licence, unless indicated otherwise in a credit line to the material. If material is not included in the article's Creative Commons licence and your intended use is not permitted by statutory regulation or exceeds the permitted use, you will need to obtain permission directly from the copyright holder. To view a copy of this licence, visit http://creativecommons.org/licenses/by/4.0/. 
(NPV) (93.2\% and 82\%). 24PTU and sCr are relevant as components for a treat-to-target strategy for LN treatment, since their high NPV corroborates their importance as good predictors of long-term renal outcome.

Keywords: Nephrology, Lupus nephritis, Lupus erythematosus, Systemic, Proteinuria

\section{Background}

Lupus nephritis (LN) occurs in about $50-60 \%$ of all patients with systemic lupus erythematosus (SLE) [1-3] and, despite the availability of guidelines and immunosuppressive treatment, kidney disease progresses to endstage renal disease (ESRD) in 10-25\% of such patients [1, $4,5]$. The identification of short-term prognostic factors predictive of poor long-term outcome in $\mathrm{LN}$ would be helpful in clinical practice and in treat-to-target strategies in clinical trials. Many studies have been conducted to identify these predictors and some of them identified 24-h proteinuria (24PTU) as the single-best predictor [6-10]. Koo et al. studied 193 Korean adult patients with renal biopsy-diagnosed diffuse proliferative LN during a mean follow-up of $13.1 \pm 5.7$ years and showed that proteinuric remission (urine protein to creatinine ratio $<0.3 \mathrm{~g} / \mathrm{g}$ or negative dipstick test) was an independent predictive prognostic marker of good renal survival and mortality [6]. Tamirou et al. [7] followed 90 patients (most of whom Caucasian) for 7 years and concluded that $24 \mathrm{PTU}<0.7 \mathrm{~g} /$ day at 12 months was the single-best predictor of good outcome, with $71 \%$ sensitivity and $75 \%$ specificity. The addition of serum creatinine $(\mathrm{sCr})$ to the model, did not significantly improve the performance of 24PTU alone, and addition of urine red blood cells reduced sensitivity from 71 to 41\% [7]. Dall'Era et al. analysed 370 patients from Aspreva Lupus Management Study (ALMS) trial and found that 24PTU $<0.8 \mathrm{~g} /$ day and levels of anti-dsDNA during treatment induction were the best predictors of renal outcome over 3 years, with the sensitivity and specificity of $24 \mathrm{PTU}$ of $81 \%$ and $78 \%$, respectively [8]. In Southeast of Brazil, Ugolini-Lopes et al. [9] followed 94 patients for 7 years and confirmed that $24 \mathrm{PTU}<0.8 \mathrm{~g} /$ day at 12 months as the best predictor of renal outcome (sensitivity $90 \%$, specificity $78 \%$ ). Addition of $\mathrm{sCr}$ and urinary red blood cells to the model of PTU in a multivariate analysis, did not improve its performance [9]. A Canadian study (2017) performed a retrospective analysis on a cohort of 101 SLE patients with $\mathrm{LN}$ in order to determine the predictive capabilities of 24PTU, and also sCr and urinary red blood cells with respect to long-term renal outcome (7 years of followup). $24 \mathrm{PTU}<0.6 \mathrm{~g} / \mathrm{d}$ and $\mathrm{sCr}<83 \mathrm{mmol} / \mathrm{L}(<0.94 \mathrm{mg} / \mathrm{dL})$ at 12 months performed independently moderately well in predicting good long-term renal outcomes while urinary red blood cell was less accurate [10]. Despite differences in studies design, criteria renal outcomes, sample size, characteristic of the study population, follow-up time, the 24PTU has remained the best early predictor of long-term LN outcome, and the cut-off of PTU was very similar between studies.

It is very important to validate PTU and $\mathrm{sCr}$ as long-term predictors of renal outcome for different populations, ethnicities, histological classes, immunological profiles, follow-up periods, and in real-life situation, especially since they are easily quantifiable with inexpensive and non-invasive laboratory methods and has been shown to reliably reflect renal injury. The renal outcomes of patients with LN vary in different ethnic groups. Brazil is a continental country with many racial, geographical and ethnic differences between regions.

The purpose of the current study was to evaluate the ability of 24PTU and $\mathrm{sCr}$ as predictors of long-term renal outcomes in a large cohort of LN patients from Northeastern Brazil.

\section{Methods}

\section{Patients}

The medical records of 414 patients with SLE previously or currently followed from 1974 to 2018 at the rheumatology division of a tertiary university hospital were reviewed. To be included in the sample, patients had to have been diagnosed with SLE according to the 2012 Systemic Lupus International Collaborating Clinics (SLICC) classification criteria [11], have no associated autoimmune disorders (such as rheumatoid arthritis, polymyositis, dermatopolymyositis, systemic sclerosis), and have been followed at the university hospital for at least one year or until their death. The prevalence of LN in our cohort of 414 patients was $53.9 \%(n=233)$. Nineteen patients were excluded because of incomplete data $(n=15)$, wrong diagnosis $(n=1)$ or overlap with systemic sclerosis $(n=3)$. We retrospectively studied all 214 patients with LN. The LN criteria for patients who have not undergone renal biopsy included the presence of two consecutive 24PTU readings $>500 \mathrm{mg}$ and an additional feature supporting active lupus such as positive serologies (hypocomplementemia and/or elevated anti-dsDNA antibodies) and/or active urinary sediment, in the absence of other causes [12]. In case of renal biopsy any class in the pathological classification of the World Health Organization/International Society of Nephrology were included as LN [13]. 


\section{Study parameters}

Information was retrieved from the patients' records, including demographic data (gender, race, age at diagnosis of SLE and LN), clinical data (SLE manifestations at any stage, time between $\mathrm{LN}$ diagnosis and the first treatment for LN, follow-up time [from diagnosis of LN to the development of chronic kidney disease, ESRD, last evaluation and/or death], induction and maintenance immunosuppressive treatment), immunological data at any time of the disease (antinuclear antibodies, IgG/IgM anticardiolipin antibodies, lupus anticoagulant, anti-dsDNA and anti-Sm antibodies), and laboratory data (serum creatinine, estimated glomerular filtration rate [eGFR], and 24PTU).

Chronic kidney disease (CKD) was defined according to the Kidney Disease Improving Global Outcome definition (eGFR $<60 \mathrm{~mL} / \mathrm{min} / 1.73 \mathrm{~m}^{2}$ for 3 months or longer irrespective of cause). End-stage renal disease was defined as the need for permanent hemodialysis or peritoneal dialysis [14]. The study protocol was approved by the institutional Research Ethics Committee and filed under number 90562917.1.3001.5045.

\section{Statistical analysis}

All statistical analyses were performed with the software Research Electronic Data Capture (RedCap) and Jamovi 2.0. The results were expressed as mean values \pm standard deviation (SD), or medians and interquartile ranges (IQR) for continuous variables and absolute numbers (percentages) for categorical variables. The level of statistical significance was set at $5 \%(p<0.05)$. Serum creatinine, eGFR and 24PTU were registered at baseline, at 3, 6 and 12 months, at 5 years and/or the last evaluation. Continuous variables were compared using the $t$ test or the Mann-Whitney test, while categorical variables were analyzed with the chi-squared test and Fisher's exact test. Receiver operating characteristic (ROC) curves were plotted and the area under the curve was calculated (Youden index) to test the performance of 24PTU and $\mathrm{sCr}$ measurements at 12 months for CKD and ERSD. The sensitivity, specificity, positive predictive value (PPV) and negative predictive value (NPV) were also calculated.

\section{Results}

This study enrolled $214 \mathrm{LN}$ patients from a single center. Most patients were female (90.6\%) and nonwhite $(78.7 \%)$, with a mean age at $\mathrm{LN}$ diagnosis of $27.3 \pm 9.2$ years. Clinical manifestations were mostly musculoskeletal (82.2\%), mucocutaneous $(73.8 \%)$, serositis $(46.7 \%)$ and leukopenia/lymphopenia $(41.5 \%)$. The ANA test was positive in 95\% (anti-dsDNA 58\%, anti-Sm $38.9 \%$, lupus anticoagulant $26.4 \%$, anticardiolipin $15.5 \%$ ).
Baseline values were registered: $\mathrm{sCr}=1.45 \pm 1.28 \mathrm{mg} /$ $\mathrm{dL} ; \quad 24 \mathrm{PTU}=2903.9 \pm 3051.3 \mathrm{mg} ; \quad$ serum albu$\min =2.51 \pm 0.78 \mathrm{~g} / \mathrm{dL} ;$ and $\mathrm{eGFR}=77.5 \pm 40.9 \mathrm{~mL} /$ $\mathrm{min} / 1.73 \mathrm{~m}^{2}$. More than half of the patients $(57.0 \%$, $122 / 214$ ) were submitted to renal biopsy. The most prevalent histological LN class was IV (53.9\%), followed by III (21.6\%). The immunosuppressive drug most frequently used to induce the first remission of LN was IV cyclophosphamide (55.6\%), followed by azathioprine (33.5\%) and mycophenolate mofetil (10.8\%). The mean follow-up period of the cohort was $11.2 \pm 7.2$ years. At the end of follow-up, 93 of 197 patients had CKD, but 49 of these 93 patients were in regular dialysis (24.8\%). Reliable information about death was obtained from 150 patients records and 20 patients had died (infections $n=5$, acute renal failure $n=2$, rupture of cerebral aneurysm $n=1$, rupture of aortic aneurysm $n=1$, bleeding $n=3$, stroke $\mathrm{n}=1$, other causes $\mathrm{n}=7$ ) (Table 1 ).

SLE patients were divided into two groups: those who developed CKD and those who remained with eGFR $>60 \mathrm{~mL} / \mathrm{min} / 1.73 \mathrm{~m}^{2}$ during follow-up. Patients were also grouped according to whether they developed ESRD, and the parameters 24PTU and $\mathrm{sCr}$ were compared at baseline, 3, 6 and 12 months, at 5 years and/ or the last evaluation (Fig. 1). Patients with and without ESRD differed significantly with regard to PTU at 12 months, but a trend towards difference has already been seen at 6 months $(p=0.06)$. During all follow-up of LN patients, CKD patients differed significantly with regard to $\mathrm{s} C r$ values.

ROC curves of $24 \mathrm{PTU}$ and $\mathrm{sCr}$ at 12 months of followup were plotted in order to identify the target that would best predict a bad long-term renal outcome (Fig. 2). The best cut-off values that maximized sensitivity and specificity for 24PTU and $\mathrm{sCr}$ as predictor of CKD were, respectively, $0.9 \mathrm{~g} / 24 \mathrm{hs}$ and $0.9 \mathrm{mg} / \mathrm{dL}$ at 12 months. ROC curve for $24 \mathrm{PTU}$ had a slightly lower performance than $\mathrm{ROC}$ curve for $\mathrm{sCr}$ as predictor for CKD (PTU $\mathrm{AUC}=0.68$; $\mathrm{sCr} \mathrm{AUC}=0.70$ ), but sensitivity and specificity values were higher for 24PTU (24PTU: sensitivity $=63.5 \%$, specificity $=71.2 \%$; $\mathrm{sCr}$ : sensitivity $=54.8 \%$, specificity $=75.3 \%$ ). When the outcome was ESRD the best cut-off points were $0.9 \mathrm{~g} / 24 \mathrm{hs}$ and $1.3 \mathrm{mg} / \mathrm{dL}$ for $24 \mathrm{PTU}$ and $\mathrm{sCr}$, respectively, and the curve performance was better for 24PTU (PTU AUC $=0.72$; $\mathrm{SCr} \mathrm{AUC}=0.61$ ) (Fig. 2). Sensitivity, specificity, positive predictive value (PPV), and negative predictive value (NPV) for bad longterm renal outcome are indicated in Table 2.

\section{Discussion}

The current study analysed $214 \mathrm{LN}$ patients from a single referral center in Northeastern Brazil followed for 11 years on average, $22.3 \%$ of whom progressed to 
Table 1 Demographics and disease related features in 214 patients with lupus nephritis

\section{Variable}

Female; $n(\%)$

$194(90.6)$

Level of schooling; $n$ (\%)

Basic literacy

$23(10.7)$

Elementary school

$33(15.4)$

High school

$58(27.1)$

College or higher

$12(5.6)$

Unknown information

$88(41.2)$

Racial distribution; $n /$ total (\%)

White

$31 / 146(21.3)$

Non-white

$115 / 146(78.7)$

Age at diagnosis of $S L E ;$ mean $\pm S D$

$25.8 \pm 8.9$

Age at diagnosis of $L N$; mean $\pm S D$

$27.3 \pm 9.2$

Time between SLE and LN diagnosis; median (IQR), months

$0(0-19.5)$

Clinical manifestation; $n$ (\%)

Mucocutaneos

$158(73.8)$

Arthritis

$176(82.2)$

Serositis

$100(46.7)$

Leukopenia/lymphopenia

$89(41.5)$

Hemolytic anemia

$41(19.1)$

Thrombocytopenia

$59(27.5)$

Neuropsychiatric

$40(18.6)$

Unknown

$4(1.9)$

Comorbidities; n (\%)

Arterial hypertension

Diabetes

Thrombosis

Biomarkers at diagnosis; $n /$ total (\%)

Antinuclear antibodies

203/214 (95)

Anti dsDNA

$47 / 81(58)$

Anti Sm

$30 / 77(38.9)$

Low levels of C3 and/or C4

$100 / 128(78.2)$

Lupus anticoagulant

Anticardiolipin

28/106 (26.4)

Serum creatinine at diagnosis of $L N$; mean $\pm S D, m g / d L$

$14 / 90(15.5)$

Proteinuria $24 \mathrm{~h}$ at diagnosis of $L N$; mean $\pm S D, m g$

$1.45 \pm 1.28$

Serum albumin at diagnosis of $\mathrm{LN}$; mean $\pm \mathrm{SD}, \mathrm{g} / \mathrm{dL}$

$2903.9 \pm 3051.3$

eGFR; mean \pm SD $\left(\mathrm{ml} / \mathrm{min} / 1.73 \mathrm{~m}^{2}\right)$

$2.51 \pm 0.78$

$77.5 \pm 40.9$

Dialysis at diagnosis of $\mathrm{LN}$; $\mathrm{n} /$ total (\%)

$12 / 192(6.2)$

Histological classification of LN (122 patients)

III; n/total (\%)

22/102 (21.6)

IV; n/total (\%)

$55 / 102(53.9)$

$V_{i}$ n/total (\%)

$14 / 102(13.7)$

Activity index; mean $\pm S D$

$7.6 \pm 4.4$

Chronicity index; mean \pm SD

$1.1 \pm 1.9$

First treatment to induction of remission; n/total (\%)

Intravenous cyclophosphamide

$108 / 194(55.6)$

Azathioprine

65/194 (33.5)

Mycophenolate mofetil

21/194 (10.8)

Follow-up duration; mean $\pm S \mathrm{D}$, years

$11.2 \pm 7.2$ 
Table 1 (continued)

\begin{tabular}{lc}
\hline Variable & $39 / 214(18.2)$ \\
\hline Complete remission after first induction of remission treatment; $n /$ total (\%) & $7 / 214(3.3)$ \\
Partial remission after first induction of remission treatment; $n /$ total (\%) & $12(6-28)$ \\
Time to achieve CR or PR; median (IQR), months & $81 / 208(38.9)$ \\
Renal relapses; $n$ /total (\%) & $44 / 197(22.3)$ \\
Chronic kidney disease; $n /$ total (\%) & $60(12-141)$ \\
Time to develop CKD; median (IQR), months & $49 / 197(24.8)$ \\
End-stage renal disease; $n$ /total (\%) & $72(20-150)$ \\
Time to develop ESRD; median (IQR), months & $20 / 150(13.3)$ \\
Death; $n$ /total (\%) & $2.1 \pm 2.0$ \\
SLICC/ACR-DI (at the end of follow-up); mean $\pm S D$ &
\end{tabular}

SLE, systemic lupus erythematosus; LN, lupus nephritis; eGFR, estimated glomerular filtration rate; CR, complete renal remission; $\mathrm{PR}$, partial renal remission; IQR, interquartile range; CKD, chronic kidney disease; ESRD, end-stage renal disease; SLICC, Systemic Lupus International Collaborating Clinics/American College of Rheumatology Damage Index

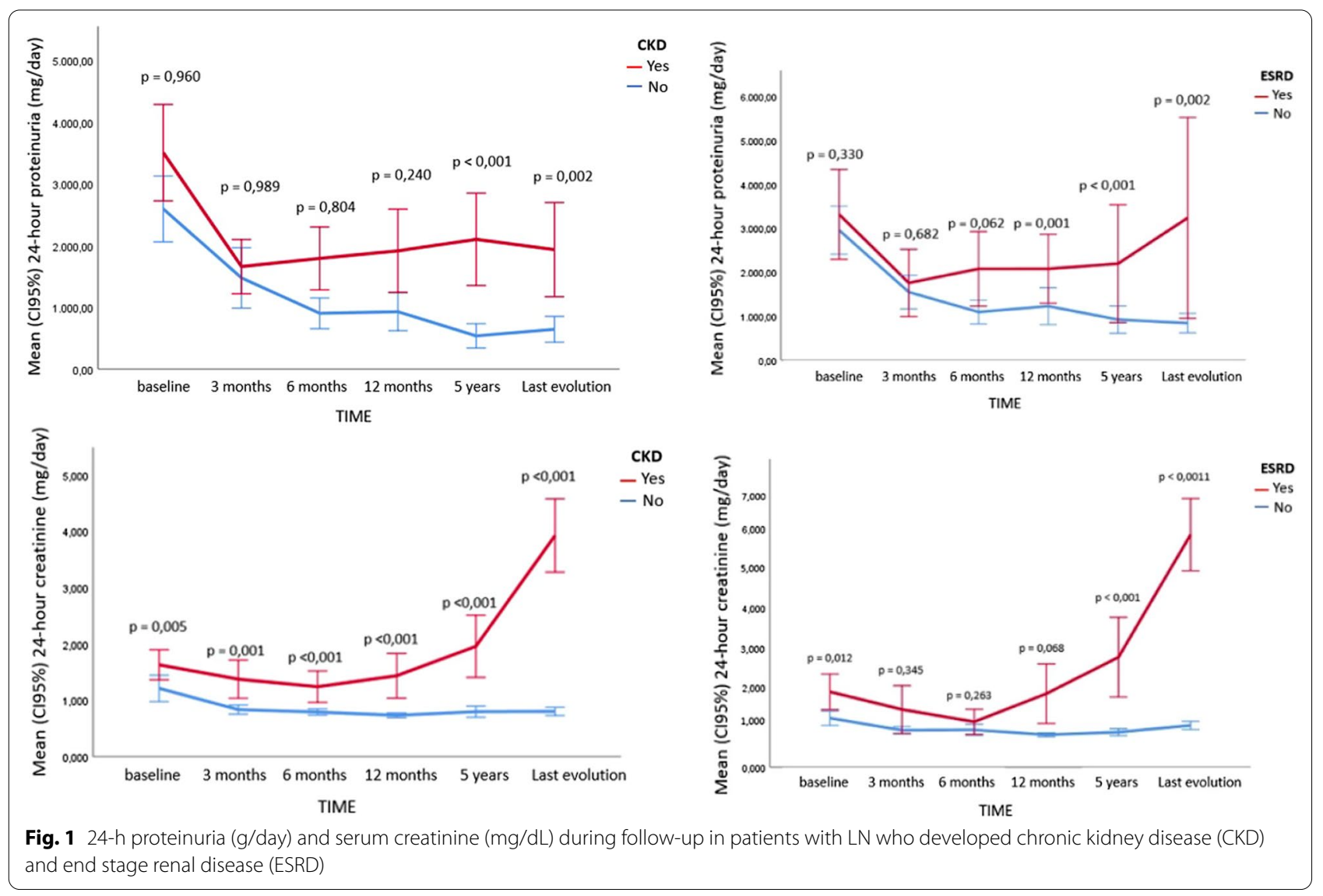

CKD and $24.8 \%$ to ESRD. This study demonstrated that achievement of a $24 \mathrm{PTU}$ value $>0.9 \mathrm{~g} /$ day at month 12 is a good predictor of a bad long-term renal outcome (CKD or ESRD), and that a $\mathrm{sCr}>0.9 \mathrm{mg} / \mathrm{dL}$ and $>1.3 \mathrm{mg} /$ $\mathrm{dL}$ at month 12 is also good predictor of CKD and ESRD, respectively.
Several clinical studies have evaluated the ability of short-term prognostic factors to predict long-term renal outcome in LN patients, such as elevated $\mathrm{sCr}$, hypertension, proteinuria, haematuria, elevated anti-dsDNA, diffuse proliferative glomerulonephritis, chronic parenchymal injury and tubulointerstitial abnormality [5-10, 

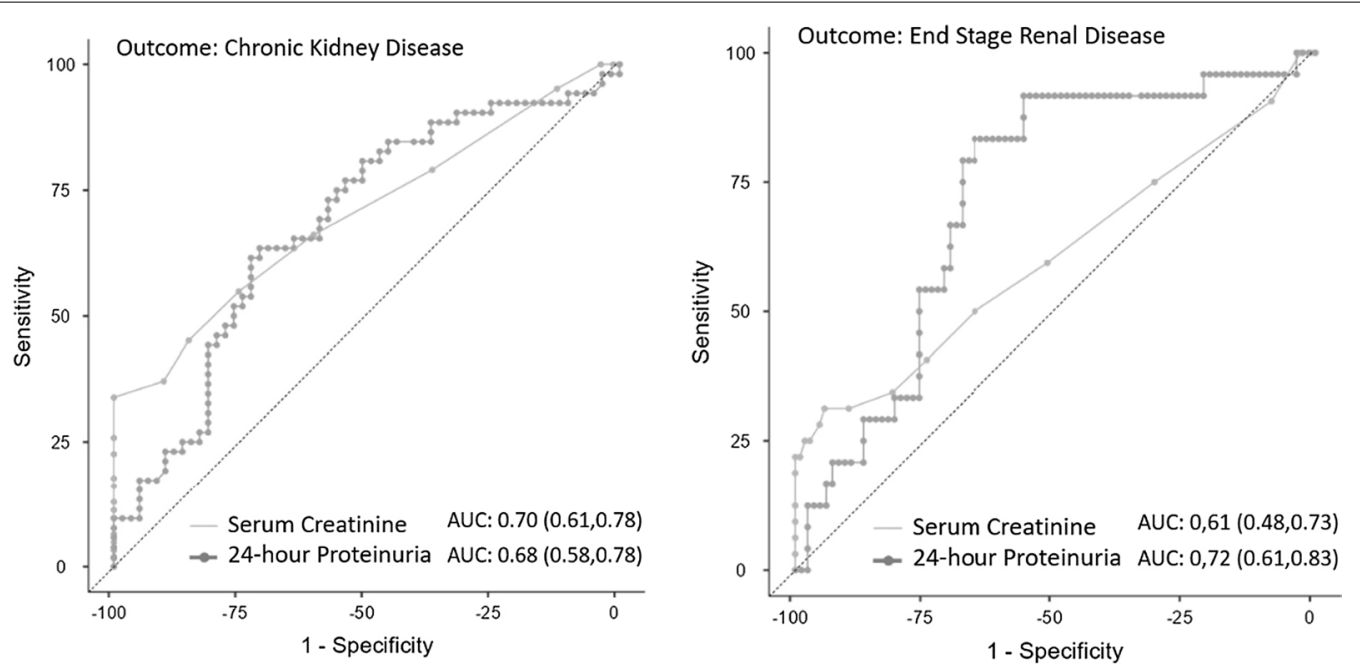

Fig. 2 Receiver operating characteristic curve of 24-h proteinuria and serum creatinine at 12 months of follow-up in patients with LN who developed chronic kidney disease and end stage renal disease

15-18]. However, PTU has recently gained prominence as the best predictor of long-term renal outcome in $\mathrm{LN}$ [6-10]. The best cut-off of 24PTU at 12 months has varied from 0.6 to $0.8 \mathrm{~g} /$ day across studies [7-10]. The renal outcomes of patients with LN vary in different ethnic groups, with the best renal prognosis in Caucasian patients, the worst in African patients and the medium in Asia and Hispanic patients [5, 18-23]. Most studies conducted to evaluate the ability of short-term prognostic factors to predict long-term renal outcome in LN patients were in white populations. A Brazilian study carried out in the Southeast of Brazil had 40.4\% non-white patients [9], while in our study carried out in the Northeast of Brazil, the population of non-whites was the vast majority (78.7\%). There are some racial, ethnic and geographical differences between the regions of Brazil, justifying the need for more studies to generalize the findings.

Studies with objectives similar to ours found 24PTU sensitivity and specificity values ranging from 58 to $90 \%$ and from 75 to $83 \%$, respectively, with cut-off points from 0.6 to $0.8 \mathrm{~g} /$ day [7-10]. Two of these used data from European clinical trials (MAINTAIN and Euro-Lupus) [7, $8]$ while the other two were retrospective analyses $[9,10]$. Clinical trials are designed for specific treatments and adherence to intervention protocols tends to be much higher than in observational studies; thus, outcomes are likely to be better than in real-life settings. In their cohort of predominantly Caucasian patients, Tamirou et al. defined good long-term outcome as $\mathrm{sCr} \leq 1.0 \mathrm{mg} / \mathrm{dL}$ at least 7 years after entry into the trial and observed that $24 \mathrm{PTU}<0.7 \mathrm{~g} /$ day at 12 months was the best predictor of good outcome, with $71 \%$ sensitivity and $75 \%$ specificity [7]. Dall'Era et al. concluded that $24 \mathrm{PTU}<0.8 \mathrm{~g} /$ day at 12 months maximized sensitivity (81\%) and specificity $(78 \%)$ for good renal outcome [8]. In our study we considered two clinical bad outcomes (CKD and ESRD) and found similar sensitivity and specificity values, but a slightly higher cut-off for 24PTU (0.9 g/day). Both trial found that the inclusion of microscopic haematuria at 12 months in the set of outcome criteria significantly decreased sensitivity. The Brazilian retrospective cohort study found a similar cut-off ( $0.8 \mathrm{~g} /$ day $)$ with a better sensitivity of $90 \%$, and also showed that the haematuria is not a good predictor of renal outcome [9]. This can be explained by the lack of standardization in the analysis of the urine sediment, delays in sample examination, the use of automated techniques instead of microscopic reading, and by the many other reasons for haematuria in a population of mainly young women. Fung et al. found a conspicuously lower cut-off $(0.6 \mathrm{~g} /$ day $)$, though at the expense of much lower sensitivity (58\%) and area under the curve [10]. The authors pointed out that their cohort had lower baseline 24PTU values than the cohorts of other studies and, in fact, baseline PTU levels were higher in the European studies (Euro-Lupus: $3.0 \pm 2.3$; MAINTAIN: $3.4 \pm 2.9)[8,10]$, in the Brazilian study $(5.4 \pm 4.5)$ [9], and in the present investigation $(2.9 \pm 3.0)$ than in the Canadian study $(2.3 \pm 2.3)$ [10]. Baseline $\mathrm{sCr}$ values were also high in the study by Ugolini-Lopes et al. $(1.73 \mathrm{mg} /$ dL) [9], and in our study $(1.45 \mathrm{mg} / \mathrm{dL})$ compared to the values reported in the MAINTAIN study $(0.95 \mathrm{mg} / \mathrm{dL})$ [7], the Euro-Lupus study $(1.15 \mathrm{mg} / \mathrm{dL})$ [8] and the Canadian study $(0.72 \mathrm{mg} / \mathrm{dL})$ [10], indicating more severe LN in Brazilian studies.

In a cohort of 1814 Chinese patients with biopsyproven $\mathrm{LN}$ followed for $7.7 \pm 5$ years, the time-average 


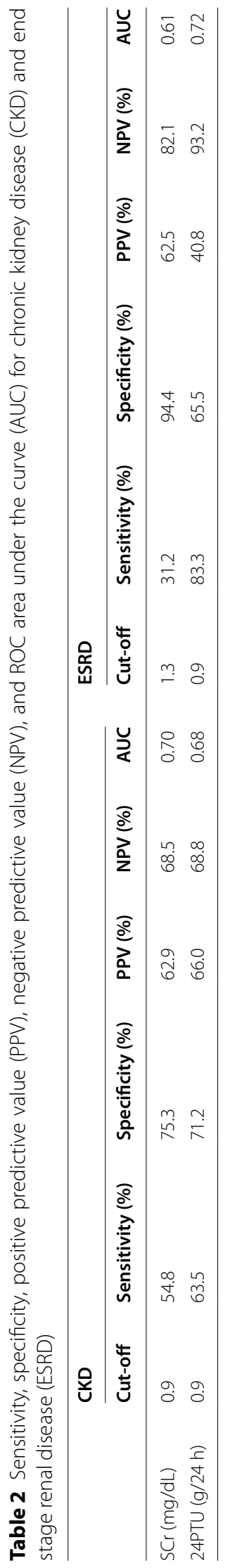


proteinuria (TA-Pro) during the follow-up was an independent risk factor for ESRD, with better predictive value than baseline PTU. The patients with TA-Pro 0.5$1.0 \mathrm{~g} / 24 \mathrm{~h}$ and TA-Pro $>1 \mathrm{~g} / 24 \mathrm{~h}$ were associated with a 12.5-fold and 237.6-fold higher risk for ESRD than those with TA-Pro $<0.5 \mathrm{~g} / 24 \mathrm{~h}$, respectively [5]. Although the methodology of this study is different from the studies already mentioned, it reinforces the importance of controlling PTU during the follow-up of patients with NL. The PTU levels should be controlled at least to $<1.0 \mathrm{~g} /$ day, and optimally to $<0.5 \mathrm{~g} /$ day.

Although the 24PTU at 12 months has been proved to be the single best predictor of long-term renal outcome $[6,7,9]$, we believe that other biomarkers are needed to impact therapeutic decision making in individual patients in the clinical, and also are needed to be used in controlled clinical trials of LN. The $\mathrm{sCr}$ at 12 months was a good predictor for long-term renal outcome in our cohort. The Canadian study suggests that while 24PTU may be more appropriate as a biomarker due its sensitivity to short-term change, there may be value in combining it with sCr [10]. Mackay et al. developed risk models to predict future adverse kidney outcomes based on clinical data acquired during the first year of therapy after diagnosis of LN. All these CKD, ESRD and severe kidney injury predictive models included PTU and $\mathrm{sCr}$ at 12 months [23]. The $\mathrm{sCr}$ values of patients developing CKD in our study were significantly higher from baseline and at 3, 6, 12 months, and during all followup than $\mathrm{sCr}$ values of patients who did not progress to CKD, suggesting that from baseline onwards $\mathrm{sCr}$ is a good predictor of renal outcome. In patients progressing to CKD and ESRD, sCr values decrease between baseline and 6 months after treatment, after which they rise again, possibly because the effective treatment of the first months is followed by a decline in immunosuppressants and corticosteroids. In short, the presence of elevated creatinine levels at the beginning of treatment suggests an increased risk of ESRD and the need to optimize immunosuppressive treatment.

An important point to note is about the high negative predictive value of $24 \mathrm{PTU}$ and $\mathrm{sCr}$ for ESRD. The probability that a patient with $24 \mathrm{PTU}<0.9 \mathrm{~g} /$ day at 12 months not progressing to ESRD is $93.2 \%$. Likewise, the probability that a $\mathrm{LN}$ patient with $\mathrm{sCr}<1.3 \mathrm{mg} / \mathrm{dL}$ at 12 months not progressing to ESRD is $82 \%$. Since predictive values depend on the prevalence of the outcome in the population being studied, these values tend to be higher in referral centers where severe patients are treated.

Our study may have been limited by the retrospective design and by the real-life setting since LN treatment heterogeneity may have influenced PTU response and outcome. Besides this, only $57 \%$ of the patients were submitted to renal biopsy. To avoid misdiagnosis of NL we strictly followed the clinical diagnostic criteria that include the presence of two consecutive 24PTU readings $>500 \mathrm{mg}$ and an additional feature supporting active lupus such as positive serologies (hypocomplementemia and/or elevated anti-dsDNA antibodies) and/or active urinary sediment, in the absence of other causes [12]. On the other hand, compared to most other studies, our sample was large and follow-up was long, with focus on 24PTU and sCr as predictors of long-term renal outcome. In addition, our patients came from a single referral center in Northeastern Brazil.

\section{Conclusion}

In a population with more severe $\mathrm{LN}$ followed for a long period ( $>10$ years), the cut-off point of PTU $>0.9$ g/day at 12 months is a good biomarker for predicting progression to CKD and ESRD. The $\mathrm{sCr}$ also is a good predictor of long-term lupus renal outcome, with a cut-off point of $0.9 \mathrm{mg} / \mathrm{dL}$ and $1.3 \mathrm{mg} / \mathrm{dL}$ for CKD and ESRD, respectively. The high NPV values for both variables emphasizes the need for a 1-year PTU and $\mathrm{sCr}$ based LN treat to target treatment as predictors of long-term renal outcome. Further studies are crucial to define the therapeutic and follow-up approach in this high risk of developing ESRD population.

\section{Abbreviations}

24-PTU: 24-h urine proteinuria; AZA: Azathioprine; CKD: Chronic kidney disease; ESRD: End-stage renal disease; LN: Lupus nephritis; MMF: Mycophenolate mofetil; NPV: Negative predictive value; PPV: Positive predictive value; ROC: Receiver operating characteristics curves; sCr: Serum creatine; SLE: Systemic lupus erythematosus.

\section{Acknowledgements}

Not applicable.

\section{Authors' contributions}

FNHFB, MMdCM and PFCBCF: contributions to the conception, design, acquisition, analysis, interpretation of data, revision of the work, approval of the submitted version and the author's own contributions. ABVJ: contribuitions to the analysis and interpretation of data and approval of the submitted version and the author's own contributions. MEdSL, LCMB, MXP, AWdSL: contributions to the acquisition of data and approval of the submitted version and the author's own contributions. All authors read and approved the final manuscript.

\section{Authors' information}

Fernanda Nogueira Holanda Ferreira Braga, Marta Maria das Chagas Medeiros: rheumatologists; phD.

Paula Frassinetti Castelo Branco Camurça Fernandes: nephrologist; phD. Antonio Brazil Viana Junior: statistical.

Matheus Eugênio de Sousa Lima, Levi Coelho Maia Barros, Marcelo Ximenes Pontes, Allysson Wosley de Sousa Lima: medical students; M.D.

\section{Funding}

Not applicable.

\section{Availability of data and materials}

The data that support the findings of this study are available at Universidade Federal do Ceará, but restrictions apply to the availability of these data, which were used under license for the current study, and so are not publicly 
available. Data are however available from the authors upon reasonable request and with permission of Universidade Federal do Ceará.

\section{Declarations}

\section{Ethics approval and consent to participate}

The study was in accordance with the ethical standards of the institutional and/or national research committee (IRB approval number 90562917.1.3001.5045) and with the 1964 Helsinki declaration and its later amendments or comparable ethical standards.

\section{Consent for publication}

Not applicable.

\section{Competing interests}

The authors declare that they have no competing interests.

\section{Author details}

${ }^{1}$ Hospital Universitário Walter Cantídio, Universidade Federal Do Ceará, Rua Capitão Francisco Pedro 1290, Rodolfo Teófilo, Fortaleza, Ceará, Brazil. ${ }^{2}$ Centro de Ciências da Saúde, Universidade Estadual Do Ceará, Avenida Dr. Silas Munguba, 1700, Itaperi, Fortaleza, Ceará, Brazil.

Received: 12 June 2021 Accepted: 21 December 2021

Published online: 04 January 2022

\section{References}

1. Hanly JG, O'Keeffe AG, Su L, Urowitz MB, Romero-Diaz J, Gordon C, et al. The frequency and outcome of lupus nephritis: results from an international inception cohort study. Rheumatology. 2016. https://doi.org/10. 1093/rheumatology/kev311.

2. Font J, Cervera R, Ramos-Casals M, García-Carrasco M, Sentís J, Herrero $C$, et al. Clusters of clinical and immunological features in systemic lupus erythematosus: analysis of 600 patients from a single Center. Sem Arthritis Rheum. 2004;33:217-30. https://doi.org/10.1053/s0049-0172(03) 00133-1.

3. Pons-Estel B, Catoggio L, Cardiel M, Soriano ER, Gentiletti S, Villa AR, et al. The GLADEL multinational Latin American prospective inception cohort of 1,214 patients with systemic lupus erythematosus. Medicine. 2004. https://doi.org/10.1097/01.md.0000104742.42401.e2.

4. Tektonidou MG, Dasgupta A, Ward MM. Risk of end-stage renal disease in patients with lupus nephritis, 1971-2015: a systematic review and Bayesian meta-analysis. Arthritis Rheumatol. 2016. https://doi.org/10.1002/art. 39594.

5. Yang J, Liang D, Zhang H, Liu Z, Le W, et al. Long-term renal outcomes in a cohort of 1814 Chinese patients with biopsy-proven lupus nephritis. Lupus. 2015. https://doi.org/10.1177/0961203315593166.

6. Koo HS, Kim S, Chin HJ. Remission of proteinuria indicates good prognosis in patients with diffuse proliferative lupus nephritis. Lupus. 2016. https://doi.org/10.1177/0961203315595130.

7. Tamirou F, Lauwerys BR, Dall'Era M, Mackay M, Rovin B, Cervera R, et al. A proteinuria cut-off level of $07 \mathrm{~g} /$ day after 12 months of treatment best predicts long-term renal outcome in lupus nephritis: data from the MAINTAIN Nephritis Trial. Lupus Sci Med. 2015. https://doi.org/10.1136/ lupus-2015-000123.

8. Dall'Era M, Cisternas MG, Smilek DE, Staub L, Houssiau FA, Cervera R, et al. Predictors of long-term renal outcome in lupus nephritis trials: lessons learned from the Euro-Lupus Nephritis cohort. Arthritis Rheumatol. 2015;1:1. https://doi.org/10.1002/art.39026.

9. Ugolini-Lopes MR, Seguro LPC, Castro MXF, Carvalho DD, Lopes AC, Borba $E F$, et al. Early proteinuria response: a valid real-life situation predictor of long-term lupus renal outcome in an ethnically diverse group with severe biopsy-proven nephritis? Lupus Sci Med. 2017. https://doi.org/10. 1136/lupus-2017-000213.

10. Fung W, Su J, Touma Z. Predictors of good long-term renal outcomes in lupus nephritis: results from a single lupus cohort. BioMed Res Int. 2017. https://doi.org/10.1155/2017/5312960.
11. Petri M, Orbai AM, Alarcón GS, Gordon C, Merrill JT, Fortin PR, et al. Derivation and validation of the Systemic Lupus International Collaborating Clinics classification criteria for Systemic Lupus Erythematosus. Arthritis Rheum. 2012. https://doi.org/10.1002/art.34473.

12. Dooley MA, Aranow C, Ginzler EM. Review of ACR renal criteria in systemic lupus erythematosus. Lupus. 2004. https://doi.org/10.1191/09612 03304lu2023oa.

13. Bajema IM, Wilhelmus S, Alpers CE, Bruijn JA, Colvin RB, Cook HT, et al. Revision of the International Society of Nephrology/Renal Pathology Society classification for lupus nephritis: clarification of definitions, and modified National Institutes of Health activity and chronicity indices. Kidney Int. 2018. https://doi.org/10.1016/j.kint.2017.11.023.

14. Stevens PE, Levin A. Evaluation and management of chronic kidney disease: synopsis of the kidney disease: improving global outcomes 2012 clinical practice guidelines. Ann Intern Med. 2013. https://doi.org/10. 7326/0003-4819-158-11-201306040-00007.

15. Kammoun K, Jarraya F, Bouhamed L, Kharrat M, Makni S, Hmida MB, et al. Poor prognostic factors of lupus nephritis. Saudi J Kidney Dis Transpla 2011. https://www.sjkdt.org/text.asp?2011/22/4/727/82660

16. Hanly JG, O'Keefe AG, Su L, et al. The frequency and outcome of lupus nephritis: results from an international inception cohort study. Rheumatology. 2016. https://doi.org/10.1093/rheumatology/kev311.

17. Nossent J, Raymond W, Kang A, Wong D, Ognjenovic M, Chakera A. The current role for clinical and renal histological findings as predictor for outcome in Australian patients with lupus nephritis. Lupus. 2018. https:// doi.org/10.1177/0961203318792361.

18. Ayodele OE, Okpechi IG, Swanepoel CR. Predictors of poor renal outcome in patients with biopsy-proven lupus nephritis. Nephrology. 2010. https:// doi.org/10.1111/j.1440-1797.2010.01290.x.

19. Faurschou M, Dreyer L, Kamper AL, Starklint H, Jacobsen S. Long-term mortality and renal outcome in a cohort of 100 patients with lupus nephritis. Arthritis Care Res. 2010. https://doi.org/10.1002/acr.20116.

20. Moroni G, Quaglini S, Gallelli B, Banfi G, Messa P, Ponticelli C. The longterm outcome of 93 patients with proliferative lupus nephritis. NDT. 2007. https://doi.org/10.1093/ndt/gfm245.

21. Korbet SM, Schwartz MM, Evans J, Lewis EJ, Collaborative Study G. Severe lupus nephritis: racial differences in presentation and outcome. JASN. 2007. https://doi.org/10.1681/ASN.2006090992.

22. Contreras G, Lenz O, Pardo V, et al. Outcomes in African Americans and Hispanics with lupus nephritis. Kidney Int. 2006. https://doi.org/10.1038/ sj.ki.5000243.

23. Mackay M, Dall'Era M, Fishbein J, Kalunian K, Lesser M, Sanchez-Guerrero $J$, et al. Establishing surrogate kidney endpoints for lupus nephritis clinical trials: development and validation of a novel approach to predict future kidney outcomes. Arthritis Rheumatol. 2019. https://doi.org/10.1002/art. 40724.

\section{Publisher's Note}

Springer Nature remains neutral with regard to jurisdictional claims in published maps and institutional affiliations.

Ready to submit your research? Choose BMC and benefit from:

- fast, convenient online submission

- thorough peer review by experienced researchers in your field

- rapid publication on acceptance

- support for research data, including large and complex data types

- gold Open Access which fosters wider collaboration and increased citations

- maximum visibility for your research: over $100 \mathrm{M}$ website views per year

At BMC, research is always in progress.

Learn more biomedcentral.com/submissions 